THURSDAY, SEPTEMBER I, 1870

\section{THE MEDICAL SCHOOLS OF ENGLAND AND GERMANY}

I.

$T^{N}$ the region of scientific medicine the Germans enjoy 1 at the present time an undisputed pre-eminence. Their medical books have taken possession of the markets of the world, and their larger schools are themselves like markets in which representatives of all countries appear, in order to exchange gold for the higher culture. Next to German books, those published in Great Britain have the best programme and apparently the widest geographical distribution. But here the enormous territory of the English language plays a very prominent part. To professional men who do not speak the English tongue, English books are but little known and still less read. In like manner, the extent to which foreigners avail themselves of the English schools is exceedingly small. It is very significant that even Americans pass by their natural market, England namely, for the acquisition of higher medical education, and resort annually in troops to Germany, where they have to contend with the disadvantage of a foreign language.

If we now attempt to ascertain the causes of this phenomenon, we must arrive at once at the conclusion that local conditions have nothing to do with it. Great Britain can number nearly as many medical schools as exist in Germany, and their local position is extremely favourable for visits from foreigners. In this respect the larger cities enjoy an enormous advantage over smaller towns, for medical students do not, as a rule, despise good living, and therefore prefer to live in great cities. Hence the medical schools of Vienna and Berlin are rendezvous for travelling physicians, while many a small German town with no less distinguished a teaching power, is visited only by those foreigners who prefer to taste the treasures of a teacher drop by drop, far from the battle of the metropolis. London alone possesses eleven medical schools. Here are also offered to the travelling disciple of science the advantages of the metropolis, and something besides which can only be obtained on the Continent by an expenditure of time and money, and then not altogether, the opportunity, namely, of changing the school, and especially of discovering the one which it will best answer his purpose to visit.

If, in spite of all this, the schools of London form no open market, the cause must be sought for in their quality. It does not, in fact, require much criticism to discover that the construction of the medical schools here is so: entirely different from that of the corresponding schools. in Germany, that the defectiveness of our language is the only excuse for designating the two by the same name. In the majority of the medical schools of London. instruction is only a subsidiary product of the general charity. The hospitals are stipported by voluntary contributions, and at one and the same time medical assistance is given to the sick and medical instruction to youths eager for knowledge. The subscribers elect officers for this purpose; and both the electors and the elected are agreed in considering the treatment of the sick as the

VOL. II. primary office, instruction as a secondary office. Professional men on the Continent are obliged to bear this relationship constantly in mind, if they would understand how it comes to pass that a nation of such sound judgment in practical life as the English, can act in a manner which, to those who look at such hospitals from the stand-point of the development of science, appears so opposed to every modern theory of work.

In these hospitals, founded and supported by voluntary contributions, the teachers, in the course of their lives, change several times the subject of their lectures. The teacher generally begins with botany, and abandons it after he has acquired a moderate knowledge by several years' instruction, in order to take up another important branch of human knowledge; and perhaps again exchanges this for something else, just at the time when he can say with Faust:-

Und sehe dass wir nichts wissen können.

The final object of such a course is the position of hospital physician or surgeon, with which, as a rule, a profitable practice is also combined. The hospitals attain in this manner the best result which they can attain. They obtain physicians who for several years have given their attention more or less assiduously to reading scientific literature. In so far as these physicians are at the same time in a wider sense useful to the community, this system performs good service in educating a large number of well-read medical men. For the development of these officers into distinguished original investigators, the mosaicwork of their course of study is altogether destructive. From the haste with which they rush through great departments of knowledge, they can give no time or leisure to assist in drawing up the endless chain of causes to the light of day. Such an undertaking, moreover, is entirely outside the aim for which the charitable contributions were given.

Among the numerous London schools, some three or four stand out conspicuously, and one of these is so constituted, from its connection with other non-medical chairs, as well as from the history of its establishment, that one may conclude the fostering of science is not in this case a secondary aim. Let us observe now what assistance is afforded by this school for this purpose ; and let us compare these means with those provided by a great German school, for instance, that of Vienna. The writer of this article has chosen this example, chiefly because he is familiar with the interior arrangements of the Vienna school. The consideration also that this is the oldest of the prominent German schools, and that its eventful history can exhibit many points of interest which stand prominently forward, has its influence. Other examples might be brought forward which would equally illustrate the contrast.

It must, in the first place, be borne in mind that the London school just referred to, that of University College, is, like all her sisters, a private institution, while the Vienna Medical School is a State institution; the Government builds or rents the building, directs it, and provides it with officers. The means for this object flow trom the provisions of the budget of the Ministry for Puilic Instruction; and the Government therefore possesses the power of granting the means of diminishing or enlarging them according to circumstances. Since many German schools, which are still Stare institutions, 
are yet entirely or partially self-supported, some words of criticism must be devoted to this system. The independent means of the Universities are not only means for the protection of their independence, but at the same time are a bulwark against the attacks of an absolute Government, hostile to science. In those states, however, where a protection against violence is provided by distinct legislation, and especially in those in which the people has a share in the Government, every other bulwark than that which the law offers is only antiquated trumpery; the independent foundations of the Universities are no better than a means for the maintenance of the spirit of caste, and for the fostering of nepotism. In Austria the independent foundations of the Universities have fallen a prey to the insatiability of the State treasury. The freedom which has so rapidly developed itself in Austria during the last few years, found the doors of the Universities open, and forthwith established herself there. Well might their noble spirit be envied by those institutions which have used their independent means for enclosing the school and the church within a common wall!

It will not require many words to prove that the state institution enjoys an advantageous position with respect to the private institution. For while, on the one hand, the State can calculate on future revenues in laying out money for the establishment of scientific institutions, the private institution must regulate itself in accordance with its actual means, and can only reckon upon much narrower materials and temporary factors. This contrast cannot be illustrated in a more striking manner than by comparing the palace which the Saxon Government has built in Leipzig for instruction in physiology, with the one or two rooms which University College, London, is able to devote to the same purpose.

It must, however, not be forgolten that it is only recently that such institutions as that at Leipzig have been established. There are, indeed, at the present moment, only three other institutions in Germany which can be compared to it, viz., the Physiological Institute at Breslau, the splendid Anatomical Institute at Berlin, and the Pathological Institute at Vienna, all of which occupy separate spacious buildings. In these and other universitics, establishments of a similar kind, and on a similar scale of completeness, are either projected or are now in course of construction.

S. STRICKER

\section{THE EARLY HISTORY OF MANKIND}

Researches into the Early History of Mankind and the Development of Civilisation. By Edward B. Tylor. Second Edition. (London: Murray, 1870.)

MR. TYLOR has devoted himself to a branch of 1 Anthropology of which there are very few students in this country, that namely which treats of the mental development of man as elucidated by his arts and customs, and especially by his myths, his superstitions, and his language. More than a third of this volume is devoted to an elaborate account of the gesture-language used by deaf mutes and savages, and to picture-writing, wordwriting, and the influence of names and images, as illustrative of various phases in the development of the human mind. After this we have chapters on the growth and decline of culture, as illustratcd by the use of stone implements of various degrees of perfection, by weapons, by modes of procuring fire, and by modifications in various domestic utensils. Then follow accounts of remarkable savage customs, such as the curing of disease by the extraction of foreign substances from the body of the patient, the prohibition of marriage with certain relations or namesakes, tabooing the names, and even avoiding the sight, of certain relations, and the extraordinary custom of the couvade. Myths, their origin and geographical distribution, are then discussed; and these varied subjects are all treated from a twofold point of view, either as giving us an insight into the laws of the development of the human mind and the growth of civilisation, or as furnishing, by their similarity over extensive areas and in widely separated countries, an argument for the common origin of the different races of man.

The work is throughout carefully written, and is illustrated by abundance of curious and little-known facts and a critical examination of their bearings. The author is very cautious in drawing any general conclusions, and when he does so carefully indicates all sources of error and uncertainty. The character of such a book cannot be fairly shown by extracts; we shall, therefore, briefly summarise one or two of the more interesting subjects and arguments.

Many persons are, no doubt, under the impression that the deaf and dumb talk to each other by means of the finger alphabet; but the use of this pre-supposes a knowledge of the meaning of words and letters, which the deaf and dumb child can hardly be taught till intelligible communication has been established with it. Alphabetical speech is slow and clumsy, whereas the deaf mute speaks to his comrades as rapidly, if not as precisely, as we do by means of vocal speech. He uses a copious and expressive language of signs, indicating words and ideas by means of simple motions and gestures. This language has the advantage of being natural and universal. English, French, and German children to a great extent understand each other, and even a North American Indian would be able to talk with them all, it being a curious fact that many of the signs used by the Indian tribes are identical with those of the deaf and dumb schools of Europe; and Mr. Tylor states that a Sandwich islander and a Chinese both made themselves understood in an American deaf and dumb institution. The "gesture language" is also connected with spoken language in two remarkable ways. Among low savage tribes there are cases in which speech has to be supplemented by gesture to make it intelligible, and it is, perhaps, reasonable to suppose that at an earlier stage of civilisation the proportion of gestures to words would be greater than it is now. There is also an agreement in some fundamental idioms. In the Aryan languages many substantives have verbal roots descriptive of some of their essential attributes. "Thus, the horse is the neigher; stone is what stands, is stable; water is that which waves, undulates; the $\mathrm{m}$ use is the stealer; and age is what goes on; the oar is what makes to go; the serpent is the creeper; and so on." Now the deaf and dumb who have no means of communication but by signs, express themselves in the same way. To them the bird is what fies, the fish what swms, the plant what sprouts out of the earth, \&c., and the motions of 